This document is the Accepted Manuscript version of a Published Work that appeared in final form in ACS Applied Materials \& Interfaces, copyright @ American Chemical Society after peer review and technical editing by the publisher. To access the final edited and published work see DOI: 10.1021/acsami.8b00047.

\title{
Squaraine Dye for Visibly Transparent All-Organic Optical Upconversion Device with Sensitivity at $1000 \mathrm{~nm}$
}

Karen Strassel, ${ }^{1,2^{*}}$ Adrian Kaiser, ${ }^{1 *}$ Sandra Jenatsch, ${ }^{3}$ Anna C. Véron, ${ }^{1}$ Surendra B. Anantharaman, ${ }^{1,5}$ Erwin Hack, ${ }^{4}$ Matthias Diethelm, ${ }^{1,5}$ Frank Nüesch, ${ }^{1,5}$ Rian Aderne, ${ }^{6}$ Cristiano Legnani, ${ }^{7}$ Sergii Yakunin, ${ }^{8}$ Marco Cremona, ${ }^{6}$ and Roland Hany ${ }^{1 * *}$ ${ }^{1}$ Empa, Swiss Federal Laboratories for Materials Science and Technology, Laboratory for Functional Polymers, CH-8600 Dübendorf, Switzerland.

${ }^{2}$ Institute of Chemical Sciences and Engineering, Ecole Polytechnique Fédérale de Lausanne, EPFL, Station 6, CH-1015 Lausanne, Switzerland.

${ }^{3}$ Fluxim AG, Katharina-Sulzer-Platz 2, 8400 Winterthur, Switzerland.

${ }^{4}$ Empa, Swiss Federal Laboratories for Materials Science and Technology, Transport at Nanoscale Interfaces, $\mathrm{CH}-8600$ Dübendorf, Switzerland.

${ }^{5}$ Institute of Materials Science and Engineering, Ecole Polytechnique Fédérale de Lausanne, EPFL, Station 12, CH-1015 Lausanne, Switzerland.

${ }^{6}$ LOEM, Optoelectronic Molecular Laboratory, Physics Department, Pontifical Catholic University of Rio de Janeiro, PUC-Rio, Rio de Janeiro, RJ, 224543-970, Brazil.

${ }^{7}$ LEO, Organic Electronics Laboratory, Physics Department, Federal University of Juiz de Fora, 36036-900 Juiz de Fora, MG, Brazil. 
${ }^{8}$ Laboratory of Inorganic Chemistry, Department of Chemistry and Applied Biosciences, ETH Zürich, CH-8093 Zürich, Switzerland.

**Correspondence should be addressed to:

Dr. Roland Hany, Empa, Laboratory for Functional Polymers, CH-8600 Dübendorf, Switzerland, Phone +41 58765 4084, E-mail roland.hany@empa.ch

Keywords: Upconverter; Photodetector; Near-Infrared; Squaraine; Organic Light-Emitting Device

\section{ABSTRACT}

Efficient light detection in the near-infrared (NIR) wavelength region is central to emerging applications such as medical imaging and machine vision. An organic upconverter (OUC) consists of a NIR sensitive organic photodetector (OPD) and an organic visible light-emitting diode (OLED), connected in series. The device converts NIR light directly to visible light, allowing pixelles imaging of a NIR scene in the visible. Here, we present an OUC composed of a NIR selective squaraine-dye based OPD and a fluorescent OLED. The OPD has a peak sensitivity at $980 \mathrm{~nm}$ and an internal photon-to-current conversion efficiency of $\sim 100 \%$. The OUC conversion efficiency $(0.27 \%)$ of NIR to visible light is close to the expected maximum. The materials of the OUC multilayer stack absorb very little light in the visible wavelength range. In combination with an optimized semitransparent metal top electrode, this enabled the fabrication of transparent OUCs with an average visible transmittance of $65 \%$ and a peak transmittance of $80 \%$ at $620 \mathrm{~nm}$. Visibly transparent OUCs are interesting for windowintegrated electronic circuits or imaging systems that allow for the simultaneous detection of directly transmitted visible and NIR upconverted light. 


\section{INTRODUCTION}

Optical sensing and imaging in the near-infrared (NIR) find many applications for communication, biological imaging, machine vision systems, non-invasive subsurface vision, passive night vision, semiconductor inspection or optical sensors for contactless industrial and consumer electronic displays. ${ }^{1-6}$ Current NIR imaging is realized by using a two-dimensional InGaAs photodetector (PD) array interconnected with a silicon readout integrated circuit. However, the integration between two separate chips is difficult, poses challenges to reduce the pixel size and leads to high manufacturing costs.

One alternative approach is to directly convert NIR radiation to visible light which can be detected by a conventional silicon charge coupled device. The basic idea of any infraredto-visible upconverter is the monolithic integration of a NIR absorber with a component emitting visible light. ${ }^{7-10}$ Major advantages are that no intermediate electronics for data processing and no external display for data visualization are required, thus drastically simplifying the portrayal of a NIR scene. In several examples, inorganic compound semiconductor or colloidal quantum dot infrared PDs were integrated with an organic light-emitting diode (OLED) and NIR light in the 1.3-1.5 $\mu \mathrm{m}$ range was converted to green light. ${ }^{11-14}$

All-organic upconverters (OUC) were demonstrated that consist of a NIR organic photodiode (OPD) combined with an OLED. ${ }^{15-17}$ In several examples, such OUCs used phthalocyanines as NIR sensitizers in combination with phosphorescent OLEDs. ${ }^{18-22}$ An upconverter was incorporated in a digital camera, and an imaging system capable of NIR as well as visible imaging was realized. ${ }^{21}$ Similarly, a system composed of an OUC and a commercial digital camera was used to produce visible images of blood vessels. ${ }^{22}$ In all these cases, NIR light below $850 \mathrm{~nm}$ was upconverted to visible light. ${ }^{15-22}$ Reported efficiencies for converting impinging NIR photons to out coupled visible photons of $2.7 \%{ }^{18}$ or $\sim 4 \%^{19}$ are limited in these OUCS 
by the external quantum efficiency (EQE) of the NIR charge generation layer, which has a maximum value of $100 \%$ for a photodiode. ${ }^{23}$ However, an advantage is that the dark current in the absence of NIR light can be very low, resulting in high signal-to-noise contrast $\left(>10^{4}\right)$ and NIR light on-off ratios. ${ }^{20}$

OUCs promise the multiple advantages of organic electronics in general and offer the potential to convert a NIR scene to a visible image using large area devices that can be realized on flexible substrates at low cost. For a widespread application range of OUCs, however, a prerequisite seems to be the extension of NIR response to longer wavelengths ( $>850$ $\mathrm{nm}$ ) than what has been demonstrated so far. Indeed, one can argue that the merits of the OUC device concept become apparent only when NIR light with wavelengths beyond the silicon band edge can be upconverted to visible light. This is because light between $\sim 700 \mathrm{~nm}$ and $1100 \mathrm{~nm}$, although not visible for the human eye, can still be detected by a conventional silicon photodetector.

NIR OPDs with spectral response above $1100 \mathrm{~nm}$ have been reported, but using organic materials that absorb also in the visible wavelength region. ${ }^{24-26}$ For OUC applications, broadband OPDs are a disadvantage and selective NIR absorption is important for two reasons. First, visible light absorption results in a non-selective NIR response of the device. Second, in combination with transparent electrodes ${ }^{27,28}$ selective NIR absorption allows for the fabrication of visibly transparent OUCs. The development of transparent OUCs is important because it allows simultaneous multi spectral imaging in the visible and NIR at the opposite side of the impinging light.

Here, we demonstrate visibly transparent OUCs that effectively upconvert NIR to visible photons at considerably longer wavelengths than what has been reported so far. In a first step, we synthesized a selective NIR squaraine dye with absorption beyond $1100 \mathrm{~nm}$. 
Squaraines are 1,3-substituted derivatives of a central electron withdrawing squaric acid core with electron rich aromatic and heterocyclic groups. Squaraines have a good photochemical, thermal, oxygen and moisture stability, and absorb light strongly with a narrow absorption band in the visible and NIR region. ${ }^{29,30}$ Squaraines have been succcessfully used in a number of technologically relevant applications such as photovoltaic devices, ${ }^{31-34} \mathrm{NIR}$ OLEDs, ${ }^{35,36}$ photodetectors and transparent phototransistors, ${ }^{37-39}$ nonlinear optics or bioimaging. $^{29}$

We then fabricated a squaraine:fullerene OPD with an internal photon-to-current conversion efficiency (IQE) at $980 \mathrm{~nm}$ of close to $100 \%$. By combining this OPD with a fluorescent $\mathrm{Alq}_{3}$-based OLED, OUCs were obtained that convert NIR photons at $980 \mathrm{~nm}$ to visible green photons with an efficiency of $0.27 \%$, close to the theoretical maximum for this OPDOLED materials combination. By replacing the mirror-like top metal with an optimized transparent electrode, we finally demonstrate OUCs with an average visible transmittance of $65 \%$ and a peak transmittance of $80 \%$ at $620 \mathrm{~nm}$. 


\section{RESULTS AND DISCUSSION}

\section{Squaraine synthesis}
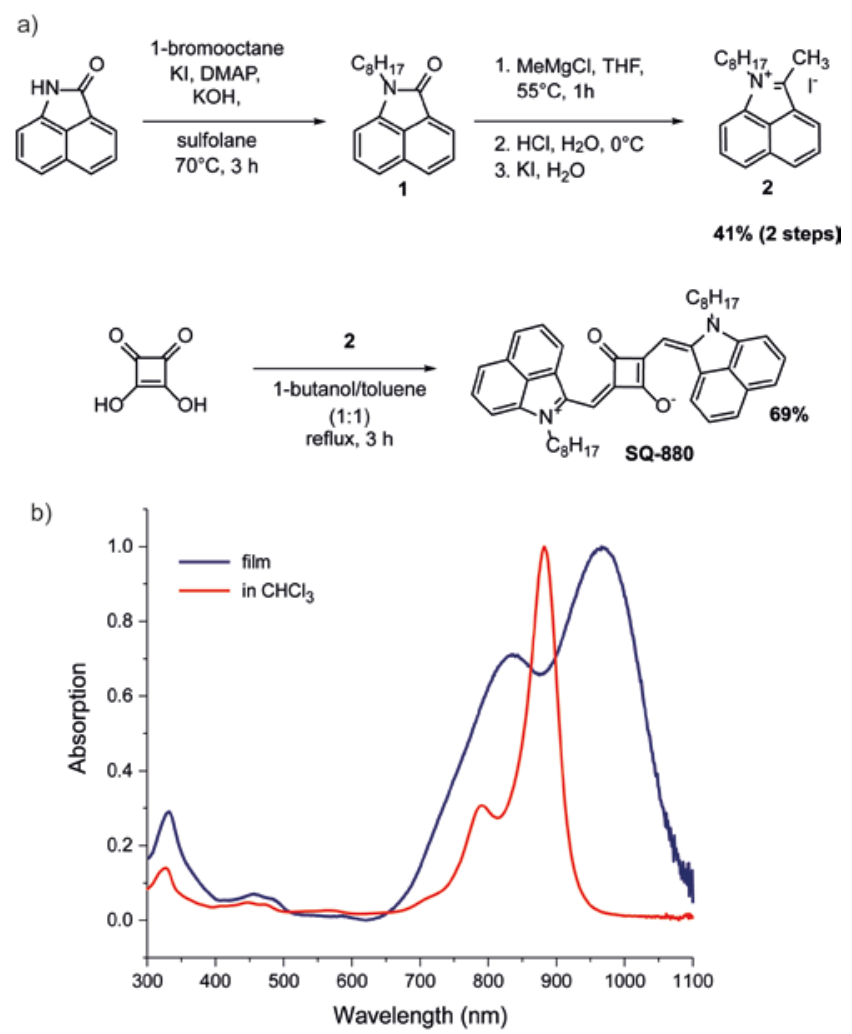

Figure 1. (a) Scheme of the synthetic route to the squaraine dye SQ-880. (b) Absorption spectra of SQ-880 in chloroform solution (red) and as a thin film on glass (blue).

The synthesis of the squaraine dye was carried out according to modified literature procedures. ${ }^{40-42}$ First, the benz[cd]indolium heterocycle 2 was synthesized in two steps (Figure 1a). Subsequently, the squaraine dye SQ-880 was obtained in $69 \%$ yield from the condensation of compound $\mathbf{2}$ with squaric acid. Detailed chemical procedures and compound analyses are described in the Supporting Information (SI-1).

SQ- 880 is a low band gap dye $\left(\lambda_{\max }=882 \mathrm{~nm}\right.$ in $\left.\mathrm{CHCl}_{3}\right)$ with a high molar extinction coefficient $\left(\varepsilon\left(\mathrm{CHCl}_{3}, \lambda(882 \mathrm{~nm})\right)=1.96 \times 10^{5} \mathrm{~cm}^{-1} \mathrm{M}^{-1}\right)$. The peak at $788 \mathrm{~nm}$ is assigned to a vibrational transition (Figure 1b). From the onset absorption $\lambda_{\text {onset }}=926 \mathrm{~nm}$, the optical band gap in $\mathrm{CHCl}_{3}$ solution $\mathrm{E}_{\mathrm{opt}}=1.34 \mathrm{eV}$ was determined. From cyclic voltammetry experiments, 
the electrochemical band gap $\mathrm{E}_{\mathrm{el}}$ was $1.06 \mathrm{eV}$. Assuming that the half-wave oxidation and reduction potentials correspond to the HOMO and LUMO levels, the redox levels vs. vacuum were calculated: SQ-880 LUMO $=-4.20 \mathrm{eV}, \mathrm{HOMO}=-5.26 \mathrm{eV}$ (Figure S1-1).

For SQ-880 films, the absorption is redshifted with a maximum at $970 \mathrm{~nm}$ (Figure $1 \mathrm{~b}$ ). The dye absorbs in a broad wavelength range of $~ 700-1100 \mathrm{~nm}$ but the absorption in the visible is small. Common estimates for the visible range are determined for photopic responses $>0.1 \%$ or $>5 \%$ peak sensitivity, resulting in visible spectral ranges of 390-720 nm or 450-670 $\mathrm{nm}^{43}$

\section{Upconverter architecture and operation mechanism}

The OUC consisted of a NIR sensitive OPD and a visible emitting OLED, stacked in series (Figure $2 \mathrm{a})$. We used either a reflective $(\mathrm{Ca}(10 \mathrm{~nm}) / \mathrm{Al}(100 \mathrm{~nm}))$ or semitransparent (Ca (2 $\mathrm{nm}) / \mathrm{Au}(8 \mathrm{~nm}) / \mathrm{Alq}_{3}(0,20$ or $55 \mathrm{~nm})$ or $\left.\mathrm{Ca}(2 \mathrm{~nm}) / \mathrm{Ag}(12 \mathrm{~nm}) / \mathrm{Alq}_{3}\right)$ top electrodes. A schematic of the device operation is pictured in Figure 2b. Both in the absence (off state) and presence (on state) of NIR light, a voltage bias is applied. In the off state electrons are blocked at the TPD/Alq 3 interface and holes are blocked at the ITO/TiO ${ }_{2}$ interface. Therefore, in the dark no current is flowing and no light emission is detected. For a high voltage bias, however, a rising dark current can already result in undesirable light emission. In the on state, NIR light is absorbed by SQ-880 in the OPD and free charge carriers are generated at the SQ-880/PCBM donor-acceptor heterojunction. Electrons are transported via $\mathrm{TiO}_{2}$ to the anode and holes are driven via a thin hole-transporting $\mathrm{MoO}_{3}$ layer into the OLED where they recombine with electrons under the emission of visible light. For the case of facile electron injection at the cathode, the overall device performance is limited by the number of 
holes produced in the OPD and the efficient conversion of NIR photons into free charge carriers is important. Therefore, we optimized in a first step the OPD performance alone.

a)

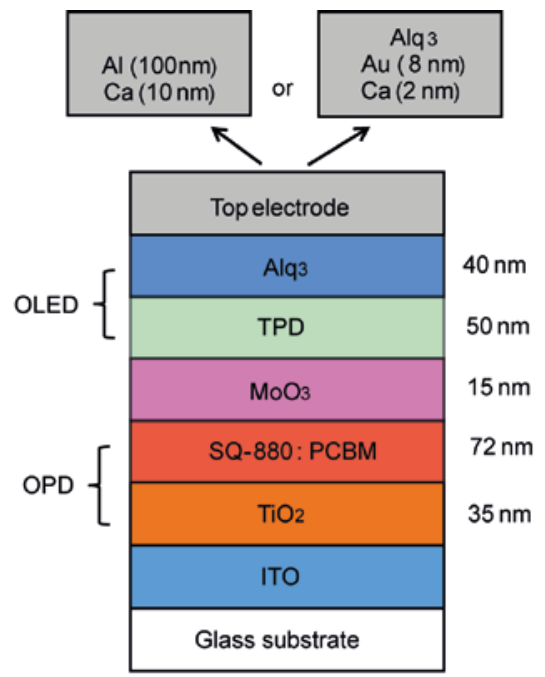

b)
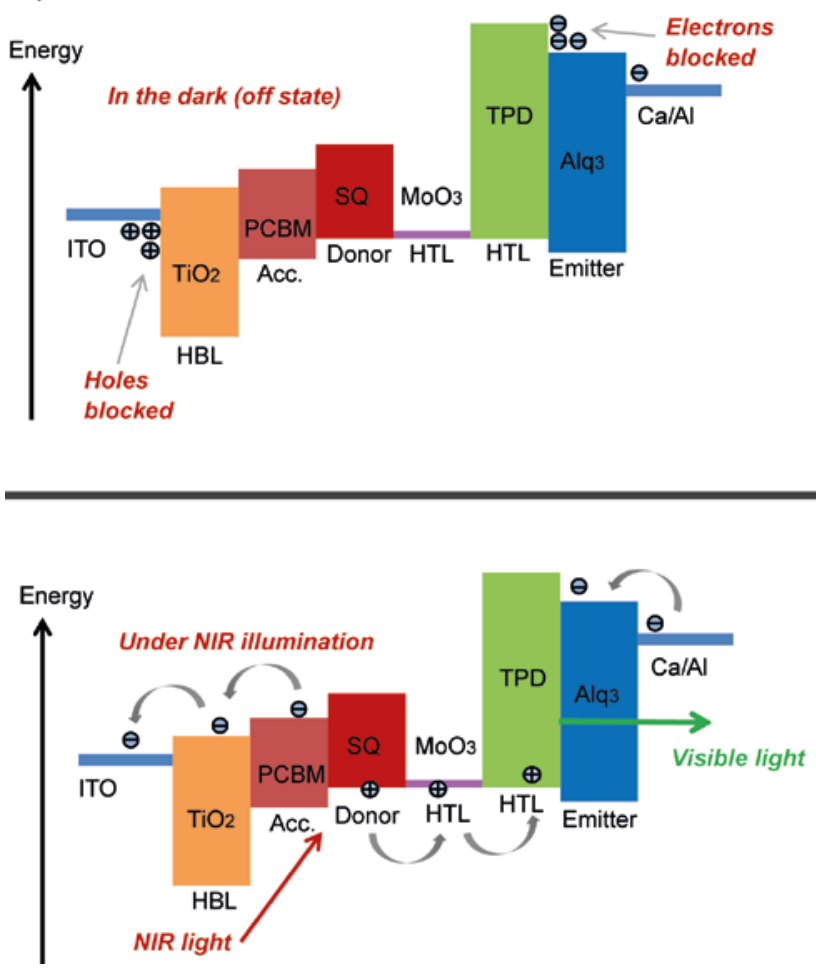

Figure 2. (a) Multilayer OUC stack with a reflective or a semitransparent top electrode. (b) Visual device operation in the absence (top) and presence of NIR light (bottom). 


\section{Photodetector properties}

The OPD device structure is shown in Figure 3a. We used a SQ-880:PCBM blend as active layer and $\mathrm{TiO}_{2}(35 \mathrm{~nm})$ and $\mathrm{MoO}_{3}(15 \mathrm{~nm})$ as electron- and hole-selective contacts. First, it was observed that the photovoltaic performance of $1: 1 \mathrm{w} / \mathrm{w}$ active films was considerably lower compared to blends with an excess of PCBM. Performances for 1:(3 - 6) w/w SQ880:PCBM blends were similar and for the best cell with a thickness of $23 \mathrm{~nm}$ we measured values for the open-circuit voltage of $\mathrm{V}_{\mathrm{oc}}=0.28 \mathrm{~V}$, the short-circuit current $\mathrm{J}_{\mathrm{sc}}=1.71 \mathrm{~mA} \mathrm{~cm}$ and the fill factor $F F=38 \%$. In the following, we fixed the SQ-880:PCBM weight ratio to $1: 3$ because fullerenes possess a significant blue-green absorption and higher PCBM amounts would compromise the final device transparency. For film thicknesses below $40 \mathrm{~nm}$, however, on average 4 out of 8 cells per device were shorted, probably due to incomplete film formation. Above $40 \mathrm{~nm}, \mathrm{~J}_{\mathrm{sc}}$ and $\mathrm{FF}$ decreased continuously and $\mathrm{V}_{\mathrm{oc}}$ increased slightly with increasing thickness. For a 1:3 w/w active layer of $72 \mathrm{~nm}$ thickness the device reproducibility was $75 \%$ and $\mathrm{V}_{\mathrm{oc}}=0.38 \mathrm{~V}, \mathrm{~J}_{\mathrm{sc}}=1.28 \mathrm{~mA} \mathrm{~cm}^{-2}, \mathrm{FF}=26 \%$ were measured.

EQE spectra for this device are shown in Figure 3b. At short-circuit the EQE in the NIR range was 3.2\%, but EQEs increased very strongly with reverse bias and reached a maximum of $84 \%$ at $980 \mathrm{~nm}$ and $-10 \mathrm{~V}$. The active film absorbs $\sim 80 \%$ of the impinging photons at this wavelength (Figure S2-3), and the IQE is consequently almost $100 \%$. In the actual OUC, the OPD is run under reserve bias (Figure $2 \mathrm{~b}$ ) and the SQ-880:PCBM material system therefore can provide near-unity conversion of NIR photons into holes that can be injected into the OLED. The efficient reductive charge transfer from excited SQ-880 to PCBM is also supported by results from photoluminescence (PL) experiments, where the dye PL $\left(\lambda_{\max }(\mathrm{em})\right.$ at 1190 $\mathrm{nm}$ ) in the SQ-880:PCBM blend film was strongly quenched (Figure S2-4). 
The NIR-sensitive OPD was also tested in a bilayer SQ-880/ $\mathrm{C}_{60}$ configuration. However, the EQE at $980 \mathrm{~nm}$ increased only marginally when applying a reverse bias and reached $7.3 \%$ at $-2 \mathrm{~V}$, much less than what we observed for the bulk heterojunction OPD. Results of bilayer OPDs and OUCs are detailed in the SI-3.

a)

\begin{tabular}{|c|}
\hline $\mathrm{Ag}$ \\
\hline $\mathrm{MoO} 3$ \\
\hline $\mathrm{SQ}-880: \mathrm{PCBM}$ \\
\hline $\mathrm{TiO}_{2}$ \\
\hline $\mathrm{ITO}$ \\
\hline Glass substrate \\
\hline
\end{tabular}

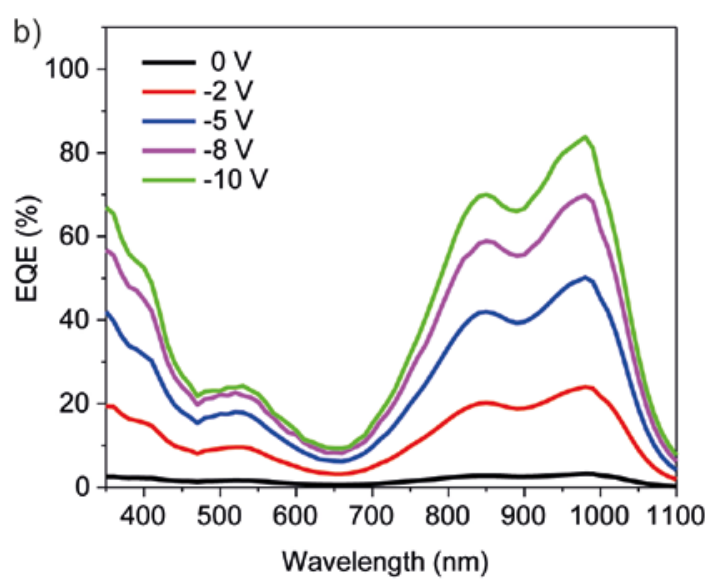

Figure 3. (a) Architecture of the NIR OPD. (b) EQEs as function of voltage bias.

\section{Upconversion device properties}

The fabrication of OUC devices (Figure $2 b$ ) is described in the SI-4. The NIR OPD was combined with a prototype OLED consisting of a single $\mathrm{Alq}_{3}$ emitting layer sandwiched between a TPD (N,N'-bis(3-methylphenyl)-N,N'-diphenylbenzidine) hole-transporting layer and a $\mathrm{Ca} / \mathrm{Al}$ electrode. ${ }^{44}$ Current-voltage-luminance (J-V-L) characteristics were measured under nitrogen atmosphere. A $980 \mathrm{~nm}$ wavelength laser $\left(49 \mathrm{~mW} \mathrm{~cm}^{-2}\right)$ was used as illumination source and 
the visible light was measured with a luminance meter. A photo of the measurement setup is shown in Figure S1-2.
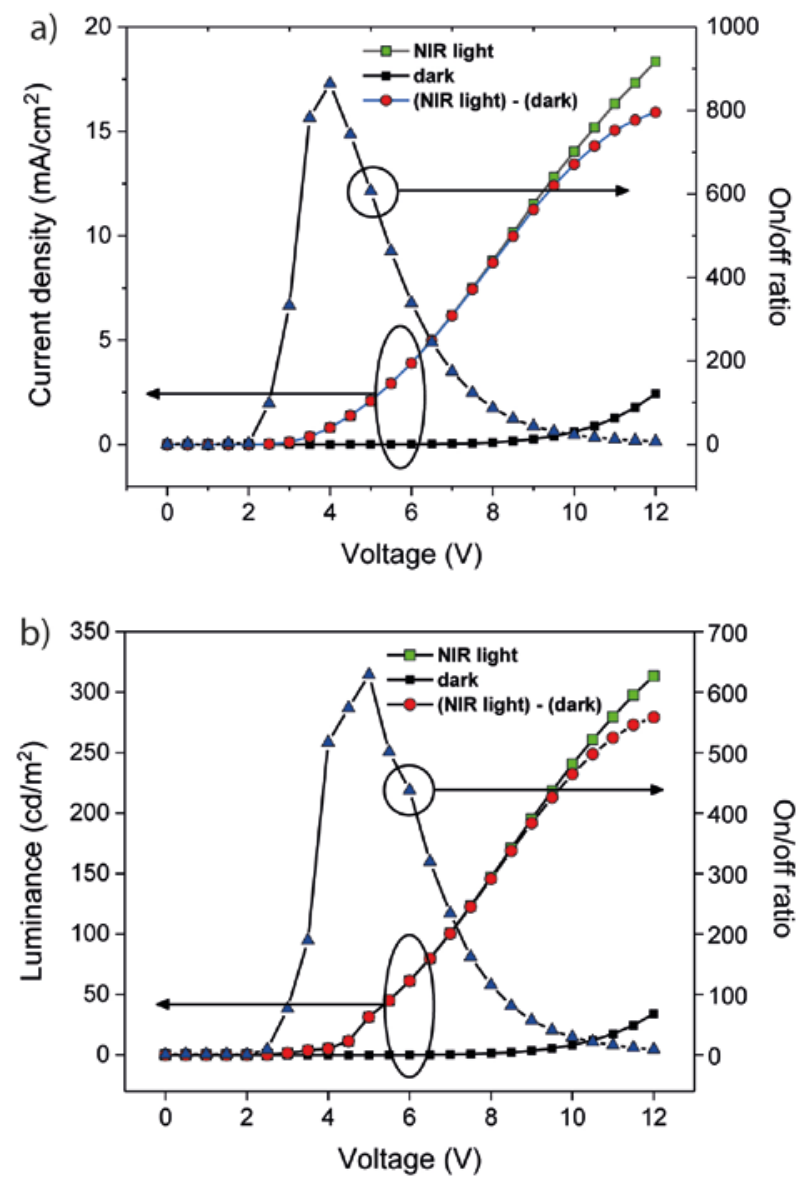

Figure 4. Characteristics of non-transparent bulk heterojunction OUCs. (a) Current and (b) luminance trends with and without NIR light.

J-V-L characteristics for an OUC with a reflective Al top electrode are shown in Figure 4. Without NIR light a pronounced dark current increase and light emission were measured only above $8 \mathrm{~V}$. In the presence of NIR light, the device turned on $\left(1 \mathrm{~cd} \mathrm{~m}^{-2}\right)$ at $2.5 \mathrm{~V}$ already and at $12 \mathrm{~V}$ the current and luminance increased to $18.4 \mathrm{~mA} \mathrm{~cm}$ and $313 \mathrm{~cd} \mathrm{~m}^{-2}$, respectively. Also indicated are the on/off ratios for the current (864 at $4 \mathrm{~V})$ and luminance (629 at 5V). Average performance values are summarized in the SI-4. 
The upconversion potential can be quantified by the ratio between the numbers of visible emitted to impinging NIR photons, the photon-to-photon-conversion efficiency P2PCE. The calculation of P2PCE is detailed in SI-5. To account only for the NIR photoninduced visible light output, the luminance originating from the dark current was subtracted before evaluating P2PCE. For the results shown in Figure 4 the P2PCE was $0.27 \%$ at $12 \mathrm{~V}$. This is in line with expectations because with the individual EQEs of the OLED $\left(\sim 0.5-1 \%{ }^{44,45}\right)$ and the OPD part ( $55 \%$ at an electric field of $12 \mathrm{~V} /$ active layer thickness), the maximum overall OUC device efficiency for our materials combination cannot exceed the range of $\sim 0.25-0.5 \%$. We also note that the calculated P2PCE represent a lower limit because with our measurement setup we can only measure the back-reflected light through the glass/ITO side and a small fraction of the emitted light is re-absorbed when passing through the OPD layers (SI-5).

\section{Transparent upconversion device}

For practical applications it is desirable that the visible image can be recorded at the opposite site of the NIR light source. Therefore, we replaced the reflective Al (100 $\mathrm{nm}$ ) top electrode with thin semi-transparent $\mathrm{Ag}(12 \mathrm{~nm})$ or $\mathrm{Au}(8 \mathrm{~nm})$ metal layers. At the same time, we added $\mathrm{Alq}_{3}(20 \mathrm{~nm}$ or $55 \mathrm{~nm}$ ) as an additional external dielectric coating to increase the device transmittance. The transmittance of metal films increases with decreasing thickness. However, a balance must be achieved between optical transparency and electrical conductivity. For $\mathrm{Ag}$, sheet resistance values of $\sim 10 \Omega$ square $^{-1}(10 \mathrm{~nm} \mathrm{Ag})^{46}$ or $\sim 40 \Omega$ square $^{-1}(12$ $\mathrm{nm} \mathrm{Ag})^{47}$ were reported. The conductivity for thin Au films seems to be even slightly higher and sheet resistances $<10 \Omega$ square ${ }^{-1}$ were measured for $10 \mathrm{~nm}$ thick Au films. ${ }^{48}$ The performance of these OUCs is summarized in the SI-4. Both for $\mathrm{Ag} / \mathrm{Alq}_{3}(20 \mathrm{~nm})$ and $\mathrm{Au} / \mathrm{Alq}_{3}(20 \mathrm{~nm})$ the luminance at $12 \mathrm{~V}$ was over $300 \mathrm{~cd} \mathrm{~m}^{-2}$, comparable with devices containing a thick $\mathrm{Al}$ 
electrode. Dark currents were however slightly higher, resulting in reduced current and luminance on/off ratios. We note that also for transparent OUCs the visible light backreflected through the glass/ITO side was measured.

Transmittance spectra of the individual materials of the OUC stack are shown in Figure $5 a$. In the visible, the transmittance of the active layer varies from $69 \%$ (at $450 \mathrm{~nm}$ ) to $85 \%$ (at $670 \mathrm{~nm}$ ) and the transmittance of the other materials is over $80 \%$. Transmittance spectra of full OUC devices with Au electrodes are shown in Figure 5b. Optical modelling (SI2) revealed that an optimized thickness $(50-60 \mathrm{~nm})$ of the external $\mathrm{Alq}_{3}$ layer results in the highest device transparency. Experimental average visible transmittance $\left(\mathrm{AVT}_{450-670}\right)$ values were $\left.55 \%(\mathrm{no} \mathrm{Alq})_{3}\right), 63.6 \%\left(\mathrm{Alq}_{3}=20 \mathrm{~nm}\right)$ and $65.1 \%\left(\mathrm{Alq}_{3}=55 \mathrm{~nm}\right)$ with a peak value of $79.9 \%$ at $620 \mathrm{~nm}$. The simulated transmittance spectra are also shown. The device photo in Figure $5 \mathrm{~b}$ demonstrates this high level of transparency. When using an $\mathrm{Ag} / \mathrm{Alq} \mathrm{q}_{3}(55 \mathrm{~nm})$ electrode, the transmittance was lower at the maximum (76.4\% at $604 \mathrm{~nm})$ and decreased strongly for longer wavelengths (Figure S2-5). Also, the AVT $450-670$ value was slightly lower for $\mathrm{Ag}(59 \%)$ compared to Au.

The P2PCEs of transparent OUCs was $0.14 \%$ (at $12 \mathrm{~V}, 20 \mathrm{~nm} \mathrm{Alq}$ ). This values are approximately a factor of two lower than for the non-transparent device. This is indeed expected because in the transparent device visible light is out coupled both in forward and backward direction, whereas the thick Al electrode mirror reflects forward emitted light towards the luminance meter that is situated at the glass/ITO side. 

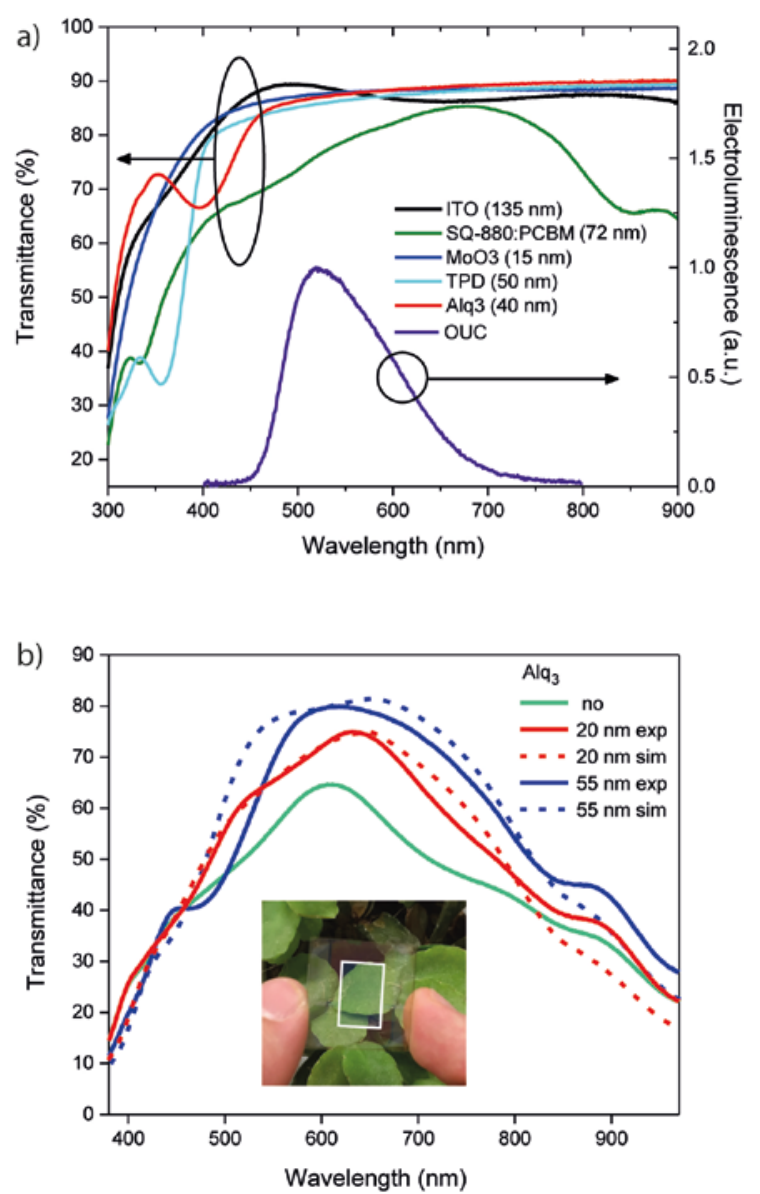

Figure 5. (a) Experimental transmittance spectra of individual materials on glass with indicated film thickness. For the UV-vis measurements, air was defined as baseline. Also shown is the OUC EL spectrum. (b) Transmittance spectra of semi-transparent OUCs with a $\mathrm{Ca}(2$ $\mathrm{nm}) / \mathrm{Au}(8 \mathrm{~nm})$ top electrode and $\mathrm{Alq}_{3}$ capping layers with different thicknesses. The dotted lines show the simulated transmittances. Also shown is a photo of an OUC with $55 \mathrm{~nm} \mathrm{Alq}$. The white rectangle indicates the $1.6 \mathrm{~cm}^{2}$ active device area.

\section{CONCLUSIONS}

OUCs are interesting for next-generation low-cost, large (or small) area NIR optical sensing and imaging applications. The core of this work is a NIR selective squaraine dye based OPD with a peak sensitivity close to $1000 \mathrm{~nm}$. Under reverse bias - the relevant operation condition when integrated into an OUC - the EQE is over $80 \%$ and the IQE is almost $100 \%$. There- 
fore, highly sensitive OUCs can be envisioned by combining the squaraine OPD with phosphorescent or thermally activated delayed fluorescent OLEDs. By using suitable OLED materials, we could also demonstrate visibly transparent OUCs with an AVT value of over 65\%. Visibly transparent OUCs are a relatively untapped field of research, but such devices allow for future applications in multi-layer sensors or on-glass integrated circuits. Transparent OUCs are also interesting because when integrated into an imaging system, directly transmitted visible light and NIR upconverted light can be detected at the same time. Our squaraine dye finally serves as a model compound to demonstrate visibly transparent OUCs that effectively upconvert light at longer wavelengths than reported so far. From the film absorption spectrum, however, it is clear that this dye is not suitable for the upconversion of light beyond $1100 \mathrm{~nm}$. We note that related NIR polymethine dyes have been demonstrated with photoresponse out to $1600 \mathrm{~nm}$, potentially offering a route to fabricate OUCs with sensitivity beyond the silicon band edge in future work. ${ }^{49,50}$

\section{ASSOCIATED CONTENT}

Squaraine synthesis, measurement details and instruments, optical experiments and modeling, bilayer OPD and OUC, fabrication of blend OUCs, calculation of the photon-to-photon conversion efficiency. The Supporting Information is available free of charge on the ACS Publications website.

\section{AUTHOR INFORMATION}

${ }^{*}$ K.S. and A.K. contributed equally.

** Corresponding author Phone: +41 58765 4084; Fax: +41 58765 1122;

E-mail: roland.hany@empa.ch 


\section{ORCID}

Roland Hany: 0000-0003-0569-119X

Karen Strassel: 0000-0002-4783-7129

Matthias Diethelm: 0000-0002-8899-1755

Anna C. Véron: 0000-0003-3699-7239

Erwin Hack: 0000-0003-1547-9889

Cristiano Legnani: 0000-0002-5234-5487

Sergii Yakunin: 0000-0002-6409-0565

Marco Cremona: 0000-0003-1306-4639

Notes The authors declare no competing financial interest

\section{ACKNOWLEDGEMENTS}

We thank Benjamin Bissig for help with reflection measurements, Nicole Pfeiffer and Thomas Geiger for support during synthesis, and the MS-team (L. Bigler) as well as Greta Patzke and David Tilley from University of Zürich for helpful discussions. Financial support from the Swiss National Science Foundation (grant number IZRJZ2_164179/1) is acknowledged. 


\section{REFERENCES}

(1) Jansen-van Vuuren, R. D.; Armin, A.; Pandey, A. K.; Burn, P. L.; Meredith, P. Organic Photodiodes: the Future of Full Color Detection and Image Sensing. Adv. Mater. 2016, $28,4766-4802$.

(2) Armin, A.; Jansen-van Vuuren, R. D.; Kopidakis, N.; Burn, P. L.; Meredith, P. NarrowBand Light Detection via Internal Quantum Efficiency Manipulation of Organic Photodiodes. Nat. Commun. 2015, 6, 6343.

(3) Siegmund, B.; Mischok, A.; Benduhn, J.; Zeika, O.; Ullbrich, S.; Nehm, F.; Böhm, M.; Spoltore, D.; Fröb, H.; Körner, C.; Leo, K.; Vandewal, K. Organic Narrowband NearInfrared Photodetectors Based on Intermolecular Charge-Transfer Absorption. Nat. Commun. 2017, 8, 15421.

(4) Arca, F.; Sramek, M.; Tedde, S. F.; Lugli, P.; Hayden, O. Near-Infrared Organic Photodiodes. IEEE J. Quantum Electron. 2013, 49 (12), 1016-1025.

(5) Sargent, E. H. Solar Cells, Photodetectors, and Optical Sources from Infrared Colloidal Quantum Dots. Adv. Mater. 2008, 20, 3958-3964.

(6) Goossens, S.; Navickaite, G.; Monasterio, C.; Gupta, S.; Piqueras, J. J.; Pérez, R.; Burwell, G.; Nikitskiy, I.; Lasanta, T.; Galán, T.; Puma, E.; Centeno, A.; Pesquera, A.; Zurutuza, A.; Konstantatos, G.; Koppens, F. Broadband Image Sensor Array Based on Graphene-CMOS Integration. Nat. Photonics 2017, 11, 366-371.

(7) Tao, J.; Chen, J.; Ban, D.; Helander, M. G.; Lu, Z. H. Optical Up-Conversion Devices for Infrared Detection and Imaging. Sci. Adv. Mater. 2012, 4, 266-281.

(8) Li, D.; Hu, Y.; Zhang, N.; Lv, Y.; Lin, J.; Guo, X.; Fan, Y.; Luo, J.; Liu, X. Near-Infrared to Visible Organic Upconversion Devices Based on Organic Light-Emitting Field Effect Transistors. ACS Appl. Mater. Interfaces 2017, 9, 36103-36110.

(9) Yu, H.; Kim, D.; Lee, J.; Baek, S.; Lee, J.; Singh, R.; So. F. High-Gain Infrared-to-Visible Upconversion Light-Emitting Phototransistors. Nat. Photonics 2016, 10, 129-134.

(10) Chen, J.; Ban, D.; Helander, M. G.; Lu, Z.-H.; Poole, P. Near-Infrared Inorganic/Organic Optical Upconverter with an External Power Efficiency of $>100 \%$. Adv. Mater. 2010, $22,4900-4904$.

(11) Ban, D.; Han, S.; Lu, Z. H.; Oogarah, T.; SpringThorpe, A. J.; Liu, H. C. Near-Infrared to Visible Light Optical Upconversion by Direct Tandem Integration of Organic LightEmitting Diode and Inorganic Photodetector. Appl. Phys. Lett. 2007, 90, 093108. 
(12) Chu, X.; Guan, M.; Niu, L.; Zeng, Y.; Li, Y.; Zhang, Y.; Zhu, Z.; Wang, B. Fast Responsive and Highly Efficient Optical Upconverter Based on Phosphorescent OLEC. ACS Appl. Mater. Interfaces 2014, 6, 19011-19016.

(13) Chen, J.; Tao, J.; Ban, D.; Helander, M. G.; Wang, Z.; Qiu. J.; Lu, Z. Hybrid Organic/Inorganic Optical Up-Converter for Pixel-Less Near-Infrared Imaging. Adv. Mater. 2012, 24, 3138-3142.

(14) Kim, D. Y.; Choudhury, K. R.; Lee, J. W.; Song, D. W.; Sarasqueta, G.; So, F. PbSe NanoCrystal-Based Infrared-to-Visibly Up-Conversion Device. Nano Lett. 2011, 11, 21092113.

(15) Tachibana, H.; Aizawa, N.; Hidaka, Y.; Yasuda, T. Tunable Full-Color Electroluminescence from All-Organic Optical Upconversion Devices by Near-Infrared Sensing. ACS Photonics 2017, 4, 223-227.

(16) Melquíades, M. C.; Aderne, R.; Cuin, A.; Quirino, W. G.; Cremona, M.; Legnani, C. Investigation of Tin(II)2,3-naphtalocyanine Molecule Used as Near-Infrared Sensitive Layer in Organic Up-Conversion Devices. Optical Mater. 2017, 69, 54-60.

(17) Chikamatsu, M.; Ichino, Y.; Takada, N.; Yoshida, M.; Kamata, T.; Yase, K. Light UpConversion from Near-Infrared to Blue using a Photoresponsive Organic LightEmitting Device. Appl. Phys. Lett. 2002, 81, 769-771.

(18) Kim, D. Y.; Song, D. W.; Chopra, N.; De Somer, P.; So, F. Organic Infrared Upconversion Device. Adv. Mater. 2010, 22, 2260-2263.

(19) Liu, S.-W.; Lee, C.-C.; Yuan, C.-H.; Su, W.-C.; Lin, S.-Y.; Chang, W.-C.; Huang, B.-Y.; Lin, C.-F.; Lee, Y.-Z.; Su, T.-H.; Chen, K.-T. Transparent Organic Upconversion Devices for Near-Infrared Sensing. Adv. Mater. 2015, 27, 1217-1222.

(20) Liu, S.-W.; Li, Y.-Z.; Lin, S.-Y.; Li, Y.-H.; Lee, C.-C. Inducing the Trap-Site in an EmittingLayer for an Organic Upconversion Device Exhibiting High Current-Gain Ratio and Low Turn-On Voltage. Org. Electronics 2016, 30, 275-280.

(21) Kim, D. Y.; Lai, T.-H.; Lee, J. W.; Manders, J. R.; So. F. Multi-Spectral Imaging with Infrared Sensitive Organic Light Emitting Diode. Sci. Reports 2014, 4, 5946.

(22) Yuan, C.-H.; Lee, C.-C.; Liu, C.-F.; Lin, Y.-H.; Su, W.-C.; Lin, S.-Y.; Chen, K.-T.; Li, Y.-D.; Chang, W.-C.; Li, Y.-Z.; Su, T.-H.; Liu, Y.-H.; Liu, S.-W. Cathodic-Controlled and Near- 
Infrared Organic Upconverter for Local Blood Vessels Mapping. Sci. Reports 2016, 6, 32324.

(23) de Arquer, F. P. G.; Armin, A.; Meredith, P.; Sargent, E. H. Solution-Processed Semiconductors for Next-Generation Photodetectors. Nat. Rev. Mater. 2017, 2, 16100.

(24) Gong, X.; Tong, M.; Xia, Y.; Cai, W.; Moon, J. S.; Cao, Y.; Yu, G.; Shieh, C.-L.; Nilsson, B.; Heeger, A. J. High-Detectivity Polymer Photodetectors with Spectral Response from $300 \mathrm{~nm}$ to $1450 \mathrm{~nm}$. Science 2009, 325, 1665-1667.

(25) Qi, J.; Han, J.; Zhou, X.; Yang, D.; Zhang, J.; Qiao, W.; Ma, D.; Wang, Z. Y. Optimization of Broad-Response and High-Detectivity Polymer Photodetectors by Bandgap Engineering of Weak Donor-Strong Acceptor Polymers. Macromol. 2015, 48, 3941-3948.

(26) Zimmerman, J. D.; Diev, V. V.; Hanson, K.; Lunt, R. R.; Yu, E. K.; Thompson, M. E.; Forrest, S. R. Porphyrin-Tape/ $\mathrm{C}_{60}$ Organic Photodetectors with 6.5\% External Quantum Efficiency in the Near Infrared. Adv. Mater. 2010, 22, 2780-2783.

(27) Makha, M.; Testa, P.; Anantharaman, S. B.; Heier, J.; Jenatsch, S.; Leclaire, N.; Tisserant, J.-N.; Véron, A. C.; Wang, L.; Nüesch, F.; Hany, R. Ternary Semitransparent Organic Solar Cells with a Laminated Top Electrode. Sci. Techn. Adv. Mater. 2017, 18, 68-75.

(28) Cao, W.; Li, J.; Chen, H.; Xue, J. Transparent Electrodes for Organic Optoelectronic Devices: a Review. J. Photonics for Energy 2014, 4, 040990.

(29) Beverina, L.; Salice, P. Squarine Compounds: Tailored Design and Synthesis Towards a Variety of Material Science Applications. Eur. J. Org. Chem. 2010, 1207-1225.

(30) Pansare, V. J.; Hejazi, S.; Faenza, W. J.; Prud'homme, R. K. Review of LongWavelength Optical and NIR Imaging Materials: Contrast Agents, Fluorophores, and Multifunctional Nano Carries. Chem. Mater. 2012, 24, 812-827.

(31) Chen, G.; Sasabe, H.; Igarashi, T.; Hong, Z.; Kido, J. Squaraine Dyes for Organic Photovoltaic Cells. J. Mater. Chem. A 2015, 3, 14517-14534.

(32) Wang, S.; Hall, L.; Diev, V. V.; Haiges, R.; Wei, G.; Xiao, X.; Djurovich, P. I.; Forrest, S. R.; Thompson, M. E. N,N-Diarylanilinosquaraines and their Application to Organic Photovoltaics. Chem. Mater. 2011, 23, 4789-4798.

(33) Chen, G.; Sasabe, H.; Sasaki, Y.; Katagiri, H.; Wang, X.-F.; Sano, T.; Hong, Z.; Yang, Y.; Kido, J. A Series of Squaraine Dyes: Effects of Side Chain and the Number of Hydroxyl 
Groups on Material Properties and Photovoltaic Performance. Chem. Mater. 2014, $26,1356-1364$.

(34) Kylberg, W.; Zhang, Y.; Aebersold, A.; Araujo de Castro, F.; Geiger, T.; Heier, J.; Kuster, S.; Ma, C.-Q.; Bäuerle, P.; Nüesch, F.; Tisserant, J.-N.; Hany, R. Oligothiophene Dendron - Decorated Squaraine Dyes: Synthesis, Thin Film Formation, and Performance in Organic Solar Cells. Org. Electronics 2012, 13, 1204-1212.

(35) Stender, B.; Völker, S. F.; Lambert, C.; Pflaum, J. Optoelectronic Processes in Squaraine Dye-Doped OLEDs for Emission in the Near-Infrared. Adv. Mater. 2013, 25, 29432947.

(36) Harkin, D. J.; Broch, K.; Schreck, M.; Ceymann, H.; Stoy, A.; Yong, C.-K.; Nikolka, M.; McCulloch, I.; Stingelin, N.; Lambert, C.; Sirringhaus, H. Decoupling Charge Transport and Electroluminscence in a High Mobility Polymer Semiconductor. Adv. Mater. 2016, $28,6378-6385$.

(37) Binda, M.; lacchetti, A.; Natali, D.; Beverina, L.; Sassi, M.; Sampietro, M. High Detectivity Squaraine-Based Near Infrared Photodetector with $\mathrm{nA} / \mathrm{cm}^{2}$ Dark Current. Appl. Phys. Lett. 2011, 98, 073303.

(38) Binda, M.; Agostinelli, T.; Caironi, M.; Natali, D.; Sampietro, M.; Beverina, L.; Ruffo, R.; Silvestri, F. Fast and Air Stable Near-Infrared Organic Detector Based on Squaraine Dyes. Org. Electronics 2009, 10, 1314-1319.

(39) Caranzi, L.; Pace, G.; Sassi, M.; Beverina, L.; Caironi, M. Transparent and Highly Responsive Phototransistors Based on a Solution-Processed, Nanometers-Thick Active Layer, Embedding a High-Mobility Electron-Transporting Polymer and a HoleTransporting Molecule. ACS Appl. Mater. Interfaces 2017, 9, 28785-28794.

(40) Waumans, B.; Callant, P. Colour Laser Marking of Articles and Security Documents. Patent WO2012171728 A1, 2012.

(41) Dust, M.; Neumann, P.; Hauser, P.; Wagenblast, G.; Benthack-Thoms, H.; Barzynski, H.; Schomann, K. D.; Kuppelmaier, H. Naphtholactamsquaric Acid Dyes and Optical Recording Materials Containing these Dyes. Patent US4830951 A, 1989.

(42) Véron, A. C. Near-Infrared Absorbing Cyanine Dyes and Organic-Inorganic Perovskites for Electronic Applications. University of Zürich, 2016, DOI:10.5167/uzh-134912.

(43) Guild, J. The Colorimetric Properties of the Spectrum. Philosophical Transactions of the Royal Society London A 1932, 230, 149-187. 
(44) Tang, C. W.; VanSlyke, S. A. Organic Electroluminescent Diodes. Appl. Phys. Lett. 1987, 51, 913-915.

(45) Mu, H.; Li, W.; Jones, R.; Steckl, A.; Klotzkin, D. A Comparative Study of Electrode Effects on the Electrical and Luminescent Characteristics of $\mathrm{Alq}_{3} / \mathrm{TPD}$ OLED: Improvements Due to Conductive Polymer (PEDOT) Anode. J. Luminescence 2007, 126, 225229.

(46) Schubert, S.; Hermenau, M.; Meiss, J.; Müller-Meskamp, L.; Leo, K. Oxide Sandwiched Metal Thin-Film Electrodes for Long-Term Stable Organic Solar Cells. Adv. Funct. Mater. 2012, 22, 4993-4999.

(47) Tian, B.; Williams, G.; Ban, D.; Aziz, H. Transparent Organic Light-Emitting Devices Using a $\mathrm{MoO}_{3} / \mathrm{Ag} / \mathrm{MoO}_{3}$ Cathode. J. Appl. Phys. 2011, 110, 104507.

(48) Wrzesniewski, E.; Eom, S.-H.; Hammond, W. T.; Cao, W.; Xue, J. Transparent Oxide/Metal/Oxide Trilayer Electrode for Use in Top-Emitting Organic Light-Emitting Diodes. J. Photonics for Energy 2011, 1, 011023.

(49) Petermann, R.; Tian, M.; Tatsuura, S.; Furuki, M. Synthesis of New Squaraine Dyes for Optical Switches. Dyes and Pigments 2003, 57, 43-54.

(50) Young, M.; Suddard-Bangsund, J.; Patrick, T. J.; Pajares, N.; Traverse, C. J.; Barr, M. C.; Lunt, S. Y.; Lunt, R. R. Organic Heptamethine Salts for Photovoltaics and Detectors with Near-Infrared Photoresponse up to 1600 nm. Adv. Opt. Mater. 2016, 4, 10281033.

\section{GRAPHICAL ABSTRACT}
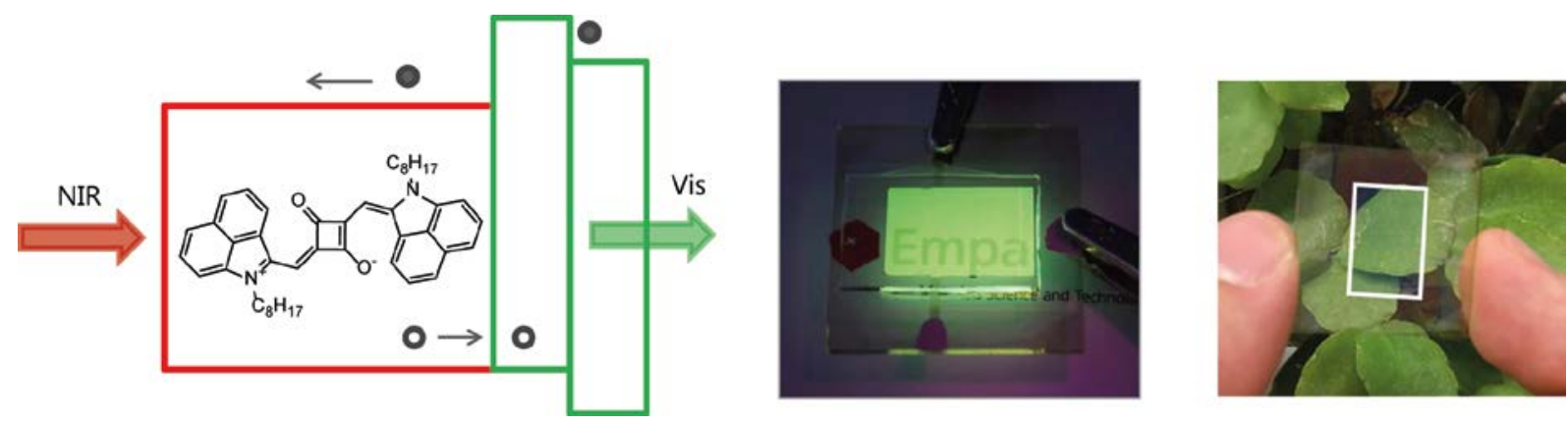